\title{
Low-Dislocation-Density GaN from a Single Growth on a Textured Substrate
}

\author{
Carol I.H. Ashby, Christine C. Willan, Jung Han, Nancy A. Missert, Paula P. Provencio, \\ David M. Follstaedt, Gregory M. Peake, and Leonardo Griego \\ Sandia National Laboratories, Albuquerque, NM 87185-1421
}

(Received

The density of threading dislocations (TD) in GaN grown directly on flat sapphire substrates is typically greater than $10^{9} / \mathrm{cm}^{2}$. Such high dislocation densities degrade both the electronic and photonic properties of the material. The density of dislocations can be decreased by orders of magnitude using cantilever epitaxy (CE), which employs prepatterned sapphire substrates to provide reduced-dimension mesa regions for nucleation and etched trenches $\boldsymbol{C}$ between them for suspended lateral growth of GaN or AlGaN. The substrate is prepatterned with narrow lines and etched to a depth that permits coalescence of laterally growing III-N nucleated on the mesa surfaces before vertical growth fills the etched trench. Low dislocation densities typical of epitaxial lateral overgrowth (ELO) are obtained in the cantilever regions and the TD density is also reduced up to 1 micrometer from the edge of the support regions.

The great potential of wide-band-gap Group III nitrides (III-N) has been limited in many applications by the very high density of treading dislocations (TDs) that form when the III-N materials are grown on latticemismatched substrates [1]. Growth of $\mathrm{GaN}$ on a planar substrate of sapphire, SiC, or $\mathrm{Si}$ (111) produces TD areal densities on the order of $10^{8}$ to $10^{10} / \mathrm{cm}^{2}$. Although such high TD densities do not appear to seriously degrade light-emitting diode (LED) performance due to the vertical character of the TDs and the short minority carrier diffusion lengths found in III-nitrides, they cause unacceptably short lifetimes for laser diodes (LDs) and excessive leakage current under reverse bias for $\mathrm{p}-\mathrm{n}$ junction devices such as field-effect transisters (FETs) and high-electron-mobility transistors (HEMTs). To solve these problems, a GaN substrate with $<10^{6}$ $\mathrm{TDs} / \mathrm{cm}^{2}$ will be required.

Several approaches have achieved considerable success in reducing TD densities to the $10^{6} / \mathrm{cm}^{2}$ range in selected regions of a wafer, but these techniques are very time-consuming to implement. These include epitaxial lateral overgrowth (ELO or LEO) $[2,3]$, pendeoepitaxy (PE) [4], and lateral overgrowth from trenches (LOFT) [5]. While each technique produces selective areas on a wafer that possess the low TD densities $\left(<10^{7} / \mathrm{cm}^{2}\right)$ required for electronic and longlived laser devices, they are complex, multistep processes requiring ex-situ deposition and etching of dielectric masks and regrowth. In each case, broad-area $\mathrm{GaN}$ is first grown on a (0001) sapphire, (0001) 6H-SiC, or $\mathrm{Si}(111)$ substrate; this initial GaN layer displays the typical $10^{8}-10^{10} / \mathrm{cm}^{2}$ TD density characteristic of standard GaN epitaxial layers and serves as the seed region for subsequent $\mathrm{GaN}$ regrowth. $\mathrm{GaN}$ grown directly over the seed region retains the initial high TD density while regions of lateral growth over the dielectric mask in ELO or from etched $\mathrm{GaN}$ walls in PE and LOFT display reduced TD densities. High concentrations of TDs are generally observed at the mask edges and both TDs and voids are common at the coalescence front over the dielectric mask.
We report a simplified approach to low-TD GaN and other III-N materials that requires a single substrate etch to form $\mu \mathrm{m}$-scale support mesas in sapphire or other substrate materials prior to a single, temperature-varied nitride growth sequence. After lowtemperature nucleation and minimal vertical growth of $\mathrm{GaN}$ to establish a $\mathrm{GaN}$ lateral surface from which to begin cantilever growth, the GaN cantilevers are grown to coalescence laterally from the mesa at a higher temperature. Cantilever epitaxy (CE) produces cantilevers with very few TDs $\left(<10^{7} / \mathrm{cm}^{2}\right)$ and appreciable suppression of TD formation above the support mesa over a distance up to $1 \mu \mathrm{m}$ inward from the mesa edge, as measured by TEM, AFM, and CL. Coalescence fronts exhibit extended regions with no TDs detectable by AFM and CL. CE has the potential of providing the first essentially "GaN substrate" with very low dislocation densities, thereby enabling more rapid development of III-N integrated circuits and long-lived laser diodes. Although it will not be discussed here, we have also grown AlGaN using $\mathrm{CE}$. In contrast, lowdefect Al-containing alloys cannot be grown using ELO because the addition of $\mathrm{Al}$ produces deposition on the dielectric mask, destroying the selectivity required for lateral growth over a "clean" dielectric surface.

In the CE process, one first etches a suitable pattern into a substrate to a depth that will permit lateral growth to span the distance between support features before vertical growth in the etched trench regions interferes with cantilever growth. We have employed sapphire wafers in our initial work, but the concepts are equally applicable to other common $\mathrm{GaN}$ substrate materials, including $\mathrm{SiC}, \mathrm{Si}(111)$, and $\mathrm{LiGaO}_{2}$.

For the samples discussed here, we have employed a $\mathrm{BCl}_{3}$-based plasma in an inductivelycoupled plasma reactor to etch approximately $2-\mu \mathrm{m}$ deep trenches into sapphire wafers. The mask was one developed for mechanistic studies of standard ELO [6] and consisted of a series of parallel lines with different mesa and trench spacings. The results presented here are 


\section{DISCLAIMER}

This report was.prepared as an account of work sponsored by an agency of the United States Government. Neither the United States Government nor any agency thereof, nor any of their employees, make any warranty, express or implied, or assumes any legal liability or responsibility for the accuracy, completeness, or usefulness of any information, apparatus, product, or process disclosed, or represents that its use would not infringe privately owned rights. Reference herein to any specific commercial product, process, or service by trade name, trademark, manufacturer, or otherwise does not necessarily constitute or imply its endorsement, recommendation, or favoring by the United States Government or any agency thereof. The views and opinions of authors expressed herein do not necessarily state or reflect those of the United States Government or any agency thereof. 


\section{DISCLAIMER}

Portions of this document may be illegible in electronic image products. Images are produced from the best available original document. 
from growths with regions masked for 4- $\mu \mathrm{m}$ supports and $8-\mu \mathrm{m}$ trenches. The strong ionic component of the plasma etch produced $2.5-\mu \mathrm{m}$ mesas with $8-9 \mu \mathrm{m}$ trenches. Two crystallographic orientations were included in the mask, with one set forming lines perpendicular to the sapphire $\{10 \overline{10}\}$ family of planes and the other perpendicular to the $\{1 \overline{2} 0\}$ family. These lead to $\mathrm{GaN}$ cantilevers that grow outward in the $[10 \overline{10}]$ and $[1 \overline{12} 0]$ directions, respectively [7].

Details of our metalorganic chemical vapor deposition (MOCVD) growth conditions for ELO have been previously reported [6] and were used for the $C E$ growths. The resulting structures consist of a $250 \AA$ LTGaN nucleation layer, $0.4 \mu \mathrm{m}$ GaN grown at $1050^{\circ} \mathrm{C}$, and the cantilevers grown at $1100^{\circ} \mathrm{C}$ for enhanced lateral growth. Results from two sample types will be described: one grown just past coalescence and another that has grown for a time sufficient to permit redistribution of $\mathrm{GaN}$ within the volume trapped by coalescence. Samples were characterized using scanning electron microscopy (SEM), transmission electron microscopy (TEM), atomic force microscopy (AFM), and cathodoluminescence (CL).

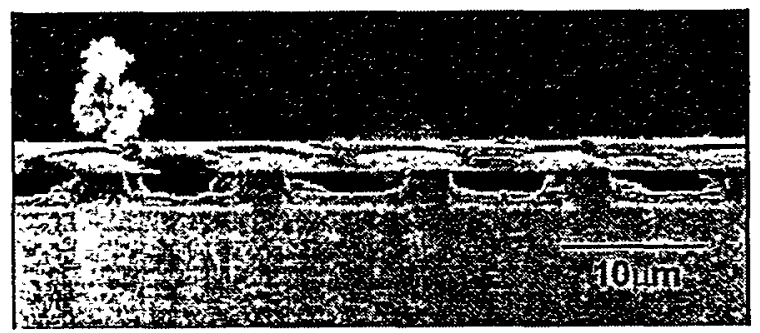

Fig. 1. Cross-section SEM micrograph of cantilever epitaxy.

Figure 1 presents an SEM image showing four and a half cantilever spans ( $2.2 \mu \mathrm{m}$ thick) of $8.4-\mu \mathrm{m}$ width over a 2.1- $\mu \mathrm{m}$-deep trench between $2.8-\mu \mathrm{m}$ supports. Both the top and bottom surfaces of the cantilever are essentially flat with the cantilever tilt being $\leq 0.1^{\circ}$ as determined by atomic force microscopy (AFM). Although a notch is present at the lower interface of two converging cantilevers just after coalescence (Fig 2), the notch is filled in as growth continues, possibly by the evaporation and redeposition of the GaN deposited in the trench before coalescence. In ELO and PE, a void that corresponds to the CE notch is observed just above the dielectric mask at the coalescence front, and a high density of TDs is observed above the void. In contrast, a significant portion of the coalescence front in CE appears to be free of TDs, as observed by cross-section TEM on the barely coalesced samples with notches and by CL on the planar surface of samples with filled notches (Fig. 3).

The relative areas of exposed $\mathrm{GaN}$ and dielectric mask, or fill factor, profoundly affect the growth rates in ELO $[6,8,9]$. The reduced consumption of reactants over the dielectric mask due to selective nondeposition results in an increase reactant supply and enhanced rates in regions with large dielectric/GaN

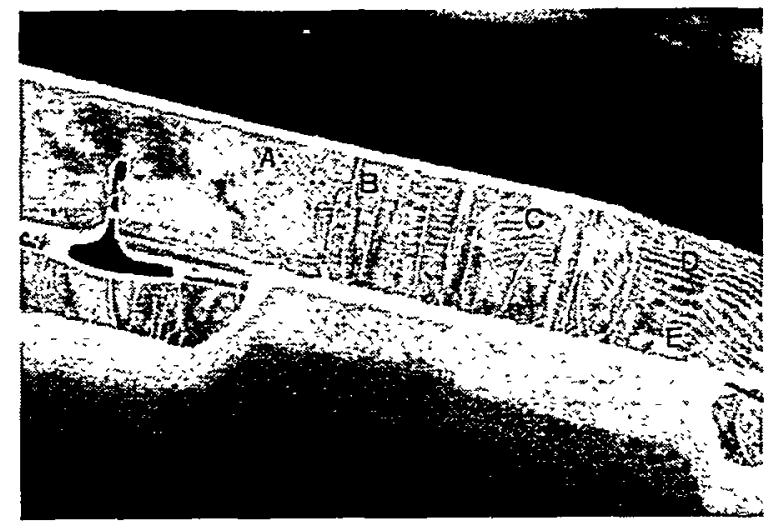

Figure 2: Cross-section TEM image of cantilever epitaxy obtained using weak beam $g=[1 \overline{12} 0]$ conditions.

ratios. Additionally, the lateral growth rate in a given region slows with time as the overgrown $\mathrm{GaN}$ occupies an increasing areal fraction. In contrast, $C E$ involves GaN-on-GaN growth during the entire growth of the cantilever. Consequently, reactant supply and concomitant growth-rate variations should not occur and no "fill-factor" effects are expected. A pronounced dependence of surface tilt on fill factor is seen in ELO [10]. The CE surfaces inspected to date appear essentially flat after coalescence.

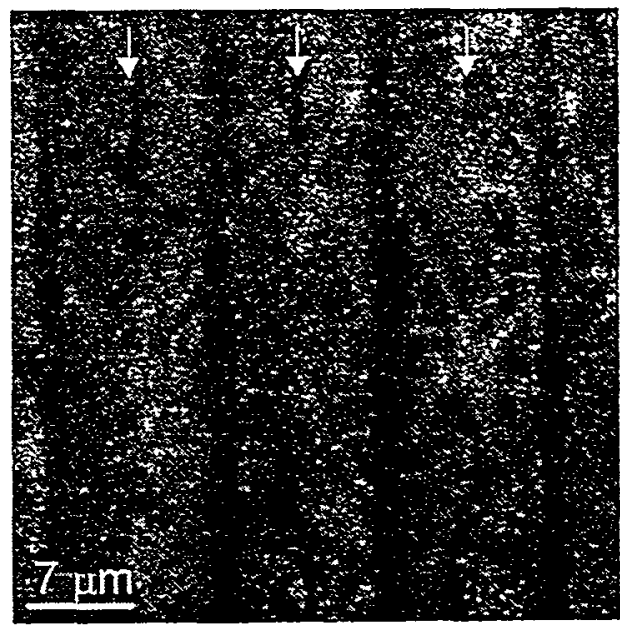

Figure $3.10 \mathrm{kV} \mathrm{CL}$ image of CE showing partial absence of TDs (dark regions) along coalescence fronts (arrows).

Figure 2 is a cross-section TEM image of a sample shortly after coalescence. No vertical TDs are observed in the cantilevers. In addition, there is a reduced number of vertical TDs over the edges of the support. TDs in these edge regions turn and extend horizontally into the cantilever. Similar turning of TDs into lateral growth regions has been reported in ELO [11] and LOFT[5]. Since TDs propagating perpendicular to the growth front may have reduced 
dislocation energies [5], this may account for the lower vertical TD density in the edge region. The horizontal TDs all appear below the coalescence point at the top of the notch. No vertical TD is observed at the coalescence front over the notch in Fig. 2. TEM, AFM, and CL measurements all indicate that a significant portion of the coalescence fronts appear to be free of vertical TDs. Plan-view CL images show an increase in brightness above the 0.5-1 $\mu \mathrm{m}$ edge region of the support mesas, consistent with a reduction in TD density [12] as inferred from the cross-section TEM images. These reduced densities are in marked contrast with ELO, where a high density of TDs occur at the coalescence front and an increase in TD density at the mask edge is observed by CL, TEM, and AFM [1].

The transition zone from a support into a cantilever is shown in the AFM image in Fig. 4. On the left, one sees the wide (up to $0.5 \mu \mathrm{m}$ ), parallel steps of the cantilever, where the step-flow growth that is characteristic of the high cantilever growth temperature has proceeded without any step pinning by TDs. Such wide individual steps are consistent with the low degree of tilt $\left(\leq 0.1^{\circ}\right)$ and are in marked contrast to the much narrower step widths $(<0.1 \mu \mathrm{m})$ seen in AFM of ELO surfaces [1].

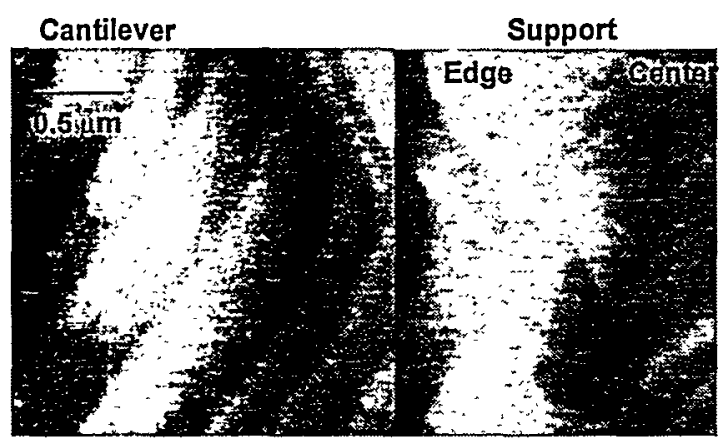

Fig 4. AFM image showing cantilever and support: composite of adjacent $2 \times 2 \mu \mathrm{m}$ scans.

Over the center of the support (right), the penetrations of mixed-character TDs $(b=1 / 3<1123>)$ at the surface are manifest as dark spots [13] corresponding to depressions and by the pinned steps that terminate at the dark-spot TDs. This is the typical appearance of GaN grown on conventional planar substrates [13]. Intermediate between these two regions is the support edge, a region between 0.5 and $1 \mu \mathrm{m}$ wide where a reduced number of mixed TDs are still seen to penetrate the surface and pin steps. In larger-area AFM scans, the angles of the steps in the cantilevers with respect to the original etched sapphire facet appear to be determined by the step-pinning at TDs in the edge region and are not constrained to a specific angle with respect to the crystal axes.

The advantages of epitaxial growth on reduced substrate areas for moderately lattice-mismatched cubic material systems, e.g., $\mathrm{SiGe}$ on $\mathrm{Si}$, have been previous described [14]. The nanometer-scale features that commensurate growth of materials with such extreme lattice mismatches as $\mathrm{GaN}$ and $\mathrm{Al}_{2} \mathrm{O}_{3}(16 \%)$ would seem, at first thought, to make this approach unfruitful. However, the extreme mismatch produces growth that is not truly commensurate, but rather the wurtzitic $\mathrm{Al}_{2} \mathrm{O}_{3}$ appears merely to provide an orientational template for subsequent $\mathrm{GaN}$ growth. In fact, in-situ measurements of the strain in $\mathrm{GaN}$ during actual growth on planar $\mathrm{Al}_{2} \mathrm{O}_{3}$ (0001) have shown that $\mathrm{GaN}$ grows with only slight tensile stress at a growth temperature of $1050^{\circ} \mathrm{C}$ [15]. Although nm-scale features would be necessary to reduce TD densities in commensurate growth, larger $\mu \mathrm{m}$-scale mesas suffice for mere orientational templating. The relatively TD-free regions within 0.5 to $1 \mu \mathrm{m}$ of the support edge suggest that further reduction of support dimensions from the $3-\mu \mathrm{m}$ to $1-\mu \mathrm{m}$ range should produce appreciable reduction of TDs above most of the support regions.

In summary, cantilever epitaxy provides an easier way to produce reduced-dislocation-density $\mathrm{GaN}$ than have previous lateral overgrowth techniques. The process yields almost dislocation-free cantilever spans. It also yields lower threading dislocation densities both at the coalescence front and at the initiation region of lateral growth than have been obtained with lateral overgrowths on dielectric masks. Pronounced reductions in dislocation densities near the support edges suggest that further improvements in the process may produce a "GaN substrate" with very low dislocation densities over the entire surface.

The authors wish to acknowledge the able technical assistance of Jeanne Sergeant and Elisa Schiermeyer. This work was supported by the U.S. Department of Energy under contract DE-AC04-94AL85000.

1J.S. Speck and S.J. Rosner, Physica B 273-274, 24 (1999).

2) D. Kapolnek, S. Keller, R. Vetury, R.D. Undenwood, P. Kozodoy, S.P. DenBaars, and U.K. Mishra, Appl. Phys. Lett. 71, 1204 (1997)

3)T.S. Zheleva, O.-H. Nam, M.D. Bremser, and R.F. Davis, Appl. Phys. Lett. 71, 2472 (1997).

4) K. Lithicum, T. Gehrke, D. Thomson, E. Carlson, P. Rajagopal, T Smith, D. Batchelor, and R. Davis, Appl. Phys. Lett. 75, 196 (1999).

5) Y. Chen, R. Schneider, S.Y. Wang, R.S. Kern, C.H. Chen, and C.P. Kuo, Appl. Phys. Lett. 75, 2062 (1999).

6) M.E. Coltrin, C.C. Willan, M.E. Bartram, J. Han, N. Missert, M.H. Crawford, A.G. Baca, MRS Internet J. Nitride Semicond. Res 4S1, G6.9 (1999).

7) R. Madar, D. Michel, G. Jacob, and M. Boulou, J. Cryst. Growth 40, 239 (1977)

8) O.-H. Nam, M.D. Bremser, T.S. Zheleva, and R.F. Davis, Appl. Phys. Lett. 71, 2638 (1997).

9) H. Marchand, J.P. Ibbetson, P.T. Fini, S. Keller, S.P. DenBaars, J.S. Speck, and U.K. Mishra, J. Cryst. Growth 195, 328 (1998).

10) P. Fini, H. Marchand, J.P. Ibbetson, S.P. DenBaars, U.K. Mishra, and J.S. Speck, J. Cryst. Growth 209, 581 (2000).

11) H. Marchand, X.H. Wu, J.P. Ibbotson, P.T. Fini, P. Kozodoy, S. Keller, J.S. Speck, S.P. DenBaars, and U.K. Mishra, Applied Phys.

Lett. 73, 747 (1998)

12) S.J. Rosner, E.C. Carr, M.J. Ludowise, G. Girolami, andH.I. Erikson, Appl. Phys. Lett. 70, 420 (1997).

13) H. Marchand, J.P. Ibbetson, P.T. Fini, P. Kozodoy, S. Keller, S. DenBaars, J.S. Speck, and U.K. Mishra, MRS-IINSR 3, 3 (1998).

14) E.A. Fitzgerald, G.P. Wilson, R.E. Proano, D.G. Ast, P.D.

Kirchner, G.D. Pettit and J.M. Woodall; J. Appl. Phys. 65, 2220

(1989).

15) S Hearne, E. Chason, J. Han, J.A. Floro, J. Figiel, and J. Hunter, Appl. Phys. Lett. 74, 356 (1999). 